\title{
Activating BRAF mutation in sclerosing mucoepidermoid carcinoma with eosinophilia of the thyroid gland: two case reports and review of the literature
}

\author{
Jasmine S. Sukumar ${ }^{1}$, Senthil Sukumar ${ }^{1}$, Darshana Purohit ${ }^{2}$, Brian J. Welch ${ }^{3}$, Jyoti Balani ${ }^{4}$, Shirley Yan ${ }^{4}$ and
} Sumitha S. Hathiramani $i^{1,5^{*}}$

\begin{abstract}
Background: Sclerosing mucoepidermoid carcinoma with eosinophilia is a rare form of thyroid carcinoma. The underlying molecular mechanisms of sclerosing mucoepidermoid carcinoma with eosinophilia tumorigenesis remain unknown.

Case presentation: We present two cases of sclerosing mucoepidermoid carcinoma with eosinophilia, both with a concurrent papillary thyroid carcinoma. Patient 1, a 70-year-old Caucasian woman, presented with sclerosing mucoepidermoid carcinoma with eosinophilia with distant renal metastasis and coexisting papillary thyroid carcinoma. Patient 2, a 74-year-old Caucasian woman with a remote history of thyroid cancer treated with thyroidectomy, presented with locoregionally invasive sclerosing mucoepidermoid carcinoma with eosinophilia and recurrent papillary thyroid carcinoma in the thyroid bed. BRAF mutation studies were performed on the sclerosing mucoepidermoid carcinoma with eosinophilia tumors. In both cases, sclerosing mucoepidermoid carcinoma with eosinophilia was positive for the BRAF V600E mutation by polymerase chain reaction. Patient 1 is the first reported case of sclerosing mucoepidermoid carcinoma with eosinophilia with renal metastasis, to the best of our knowledge.

Conclusions: Our findings suggest, for the first time, to our knowledge, involvement of the RAS-RAF-MEK-ERK signaling pathway in the pathogenesis of sclerosing mucoepidermoid carcinoma with eosinophilia. Thus, BRAF inhibitors may prove to be a useful targeted medical therapy in the treatment of a subset of patients with aggressive sclerosing mucoepidermoid carcinoma with eosinophilia tumors who exhibit BRAF activating mutation.
\end{abstract}

Keywords: Thyroid cancer, Sclerosing mucoepidermoid carcinoma with eosinophilia, BRAF, V600E, Renal metastases

\section{Background}

Sclerosing mucoepidermoid carcinoma with eosinophilia (SMECE) is a rare subtype of thyroid carcinoma of adults first reported in 1991 [1]. It is more common in women, occurs between ages 58 and 71 years old, and almost always occurs in a background of lymphocytic thyroiditis [2]. SMECE is characterized morphologically by extensive sclerosis and squamous and glandular differentiation with

\footnotetext{
* Correspondence: sumitha.hathiramani@va.gov

'Department of Internal Medicine, UT Southwestern Medical Center, 5323 Harry Hines Boulevard, Dallas, TX 75390, USA

${ }^{5}$ Division of Endocrinology, VA North Texas Healthcare System, 4500 South Lancaster Road, Dallas, TX 75216, USA

Full list of author information is available at the end of the article
}

inflammatory infiltrate rich in eosinophils. Although SMECE shares several morphologic features with mucoepidermoid carcinoma (MEC), including squamous and glandular differentiation, MEC has noninflamed stroma devoid of eosinophilic infiltration [3]. Furthermore, on immunohistochemistry, MEC stains positive for thyroglobulin, whereas SMECE is usually positive for cytokeratin (CK) and mucin but negative for thyroglobulin and calcitonin. Positive staining for carcinoembryonic antigen (CEA) and p63 has also been reported in SMECE [1].

Clinically, SMECE often behaves in an indolent manner, but aggressive cases have been reported $[1,4]$. It can be locoregionally invasive in the neck, though distant

(c) The Author(s). 2019 Open Access This article is distributed under the terms of the Creative Commons Attribution 4.0 International License (http://creativecommons.org/licenses/by/4.0/), which permits unrestricted use, distribution, and 
metastases have also been described. Surgical resection, based on the extent of invasion of the tumor, is currently the therapy of choice. Other treatment modalities that have been used with limited benefit include external beam radiation, traditional chemotherapy (such as carboplatin, doxorubicin, paclitaxel, and methotrexate), and radioactive iodine $[1,5-7]$.

Little is known about the underlying molecular mechanisms of SMECE tumorigenesis [2]. A recent study demonstrated that SMECE did not harbor mutations and translocations commonly involved in thyroid carcinogenesis, indicating that SMECE is likely molecularly and morphologically distinct from other thyroid tumors.

We report two interesting cases of SMECE with concurrent papillary thyroid carcinoma (PTC), both harboring the B-Raf proto-oncogene, serine/threonine kinase $(B R A F)$ V600E activating mutation in the SMECE tumor. This novel finding suggests, for the first time, to our knowledge, involvement of the RAS-RAF-MEK-ERK signaling pathway in the pathogenesis of SMECE.

Institutional review board exemption was obtained per institutional protocol prior to the reporting of these two cases.

\section{Case presentation}

\section{Patient 1}

A 70-year-old Caucasian woman presented with a 2month history of dysphagia, unintentional weight loss, and hoarseness. Physical examination revealed a right-sided thyroid mass. Computed tomography (CT) showed a large right thyroid mass arising from the posterior margin, invading the cricoid cartilage, and abutting the esophagus and trachea, measuring $3 \mathrm{~cm} \times 2.7 \mathrm{~cm}$. Laryngoscopy revealed a paralyzed right vocal cord and a right subglottic mass. Fine-needle aspiration of the thyroid mass revealed histology consistent with PTC. Preoperative positron emission tomography (PET) did not show distant metastasis, although the finding was significant for right kidney hydronephrosis. She was taken to the operating room with intent to perform total thyroidectomy with locoregional debulking. However, intraoperative frozen pathology of the involved recurrent laryngeal nerve and a level VI lymph node were concerning for squamous cell carcinoma. Given this unexpected intraoperative diagnosis, she subsequently underwent total thyroidectomy with bilateral neck dissection and laryngopharyngectomy with sacrifice of the right and left recurrent laryngeal nerves. The patient also underwent percutaneous endoscopic gastrostomy and tracheostomy tube placement.

Final surgical pathology showed an amended report consistent with a background of lymphocytic thyroiditis, PTC in the right thyroid lobe with largest dimension 4.2 $\mathrm{cm}$, and SMECE in the inferior right thyroid lobe with largest dimension $3.5 \mathrm{~cm}$. The anterior margin was positive for SMECE, and the posterior margin was positive for both
PTC and SMECE. A second PTC focus of $0.5 \mathrm{~cm}$ was noted in the left thyroid lobe (negative margins). There were 10/ 53 lymph nodes in the neck involved with PTC (2/7 right central neck, 5/30 right levels II-V, 1/1 tracheal node, and 2/15 left neck level II/IV). SMECE was found infiltrating the right and left recurrent laryngeal nerves, paratracheal fibrous tissue, and posterior tracheal wall with extension to the deep submucosa. By immunohistochemistry, SMECE stained negative for thyroid transcription factor-1 (TTF-1) and thyroglobulin and positive for CK7, CK AE1/AE3, CK19, and CEA. We also tested the thyroid specimen for BRAF V600E mutation by polymerase chain reaction (PCR), and it was found to be positive in both the PTC and SMECE tumors of the thyroid.

Three months after initial presentation, the patient received ablation with $154.2 \mathrm{mCi}$ of radioactive iodine $\left({ }^{131} \mathrm{I}\right)$ for treatment of the PTC. A post-therapy wholebody scan done 1 week later showed focal uptake at the midline of the lower neck consistent with residual thyroid tissue or functioning metastasis, without evidence of distant metastatic disease.

One month after ${ }^{131} \mathrm{I}$ ablation, the patient's PET/CT scan revealed an interval development of a fluorodeoxyglucose avid $1.5-\mathrm{cm}$ pulmonary nodule adjacent to left hilum within the left upper lobe and an $8 \times 5-\mathrm{cm}$ mass in the lower pole of the right kidney, which was biopsied (Fig. 1). The biopsy was morphologically consistent with metastatic SMECE (Fig. 2), and the tumor was also positive for BRAF V600E mutation. Two months after the ${ }^{131} \mathrm{I}$ ablation, the patient received adjuvant external beam radiation. She received 54 Gy at 1.8 Gy per fraction to bilateral neck levels 2-6 along with superior mediastinal nodes. The thyroid bed, right neck levels 2-5, left neck levels 24 , and peritracheal nodes went up to 60 Gy at 2 Gy per fraction. Repeat CT of the chest 1 year after initial presentation showed a new left suprahilar $3.2 \mathrm{~cm} \times 2.3-\mathrm{cm}$ mass with innumerable pulmonary nodules, increase in size of pleura-based density at the right lower lobe base of $3.8 \times$ $1.1 \mathrm{~cm}$, and left hilar lymphadenopathy. She presented

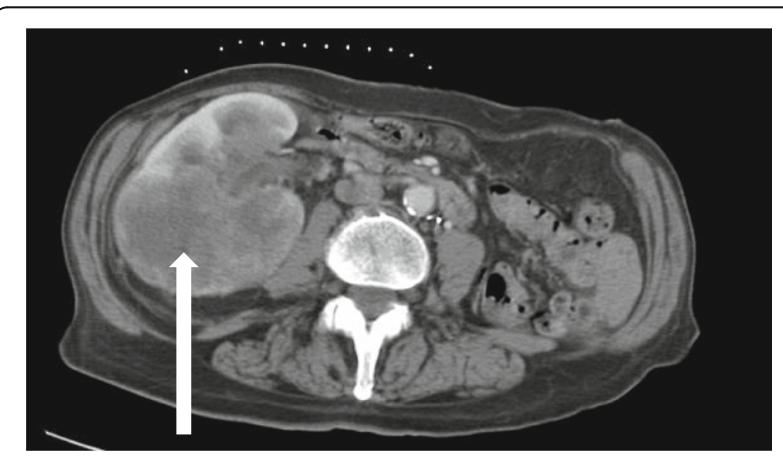

Fig. 1 Axial computed tomography of the abdomen of patient 1 at the level of kidneys showing right renal metastases of primary thyroid sclerosing mucoepidermoid carcinoma with eosinophilia (arrow) 

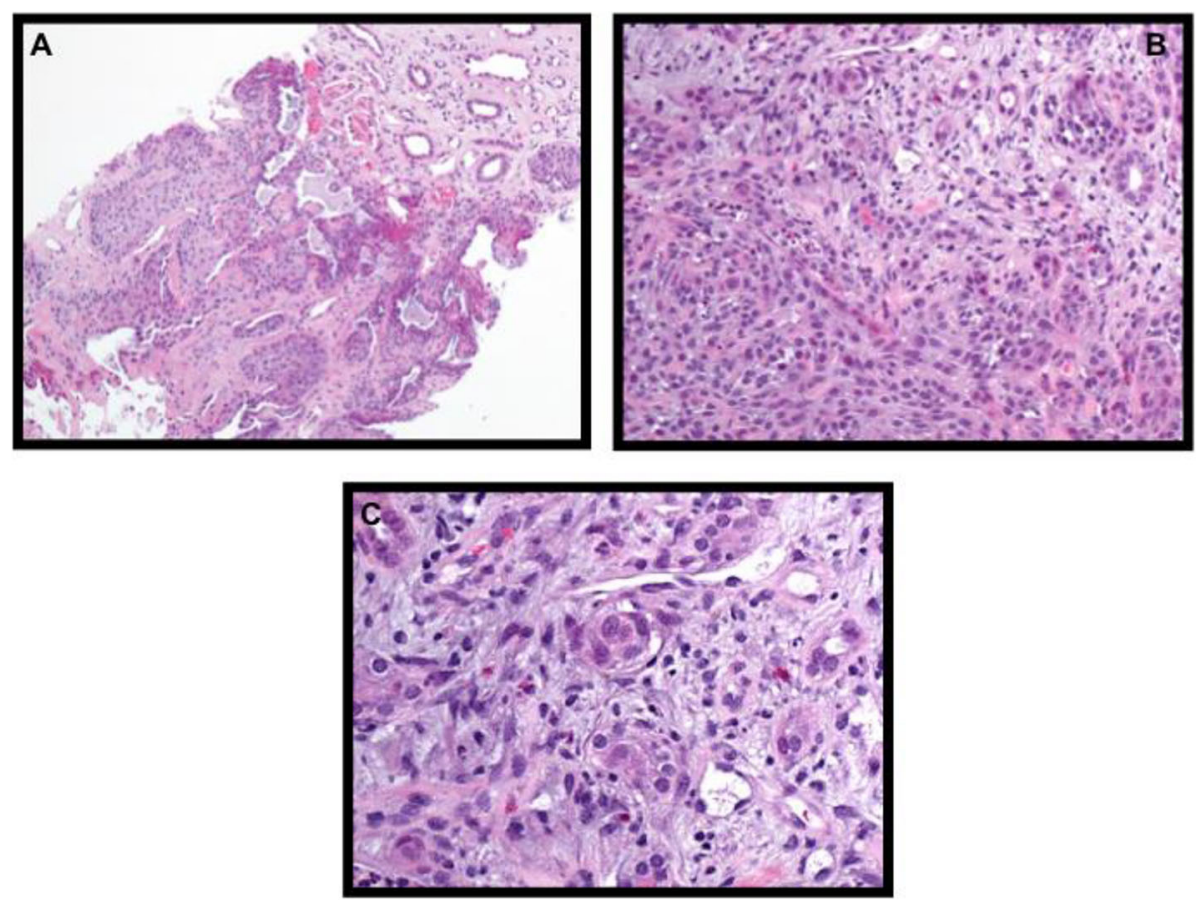

Fig. 2 Pathology from right kidney biopsy of patient 1 shows sclerosing mucoepidermoid carcinoma with eosinophilia consistent with pathology from primary thyroid tumor. Histology shows (a) mucoid changes (hematoxylin and eosin (H\&E) stain; original magnification, $\times 10$ ), (b) epidermoid desmoplasia (hematoxylin and eosin (H\&E) stain; original magnification, $\times 20$ ), and (c) eosinophils present in inflamed stroma (hematoxylin and eosin (H\&E) stain; original magnification, $\times 40$ )

several times for failure to thrive, which was thought secondary to the radical surgery. Her course was also complicated by acute renal failure and hematuria. Given rapid growth of metastatic lesions and declining functional status, she pursued hospice care and subsequently died within 1 year of diagnosis.

\section{Patient 2}

A 73-year-old Caucasian woman with a history of PTC treated with total thyroidectomy at the age of 34 years presented to an outside institution with a recurrent right neck mass. She had not been routinely seen by any providers until this recurrence. She underwent right neck dissection, but the mass was found to be adherent to the carotid artery and esophagus, precluding complete resection. Pathology again revealed PTC. This was followed by treatment with $150 \mathrm{mCi}$ of ${ }^{131} \mathrm{I} 2$ months postoperatively with subsequent whole-body scan uptake in the thyroid bed without evidence of distant metastasis. She was offered adjuvant external beam radiation to the neck but declined.

One year later, CT of the neck revealed a heterogeneously enhancing and partially necrotic mass within the right thyroidectomy bed extending posteriorly to the esophagus and involving the right recurrent laryngeal nerve. The mass measured $2.2 \times 3.0 \times 2.8 \mathrm{~cm}$ in its respective anterior-posterior, transverse, and craniocaudal dimensions. She was referred to our institution for surgical resection and underwent right radical neck dissection and wide local excision of the neck mass, though it was noted that residual tumor plaque on the carotid and trachea were unable to be fully resected.

Pathology revealed components of both classic PTC and SMECE. There was also a background of lymphocytic thyroiditis, and the tumor involved all margins, indicating that the tumor likely arose from a thyroid remnant. Upon immunohistochemistry, both PTC and SMECE stained positive for CK AE1/AE3 and negative for calcitonin. The PTC component stained positive for thyroglobulin, whereas SMECE was negative (Fig. 3). The SMECEinvolved areas of the specimen were scattered to diffusely positive for CK5/6 and p63. BRAF V600E mutation was identified by PCR in both the PTC and SMECE tumors. The patient continued to follow up with her outside provider and had another treatment with ${ }^{131}$ I. Unfortunately, the dose of ${ }^{131} \mathrm{I}$ administered and the post-therapy whole-body scan result were not available.

She did well until 11 months postoperatively, when she began to notice swallowing difficulty. Repeat CT of the neck revealed a mass in the region of the thyroid bed posterior to the trachea. These findings were confirmed on a PET scan. The patient underwent a right and left radical neck dissection with laryngectomy, though again the tumor was not able to be fully resected, because it was densely adherent to the carotid and innominate arteries. 

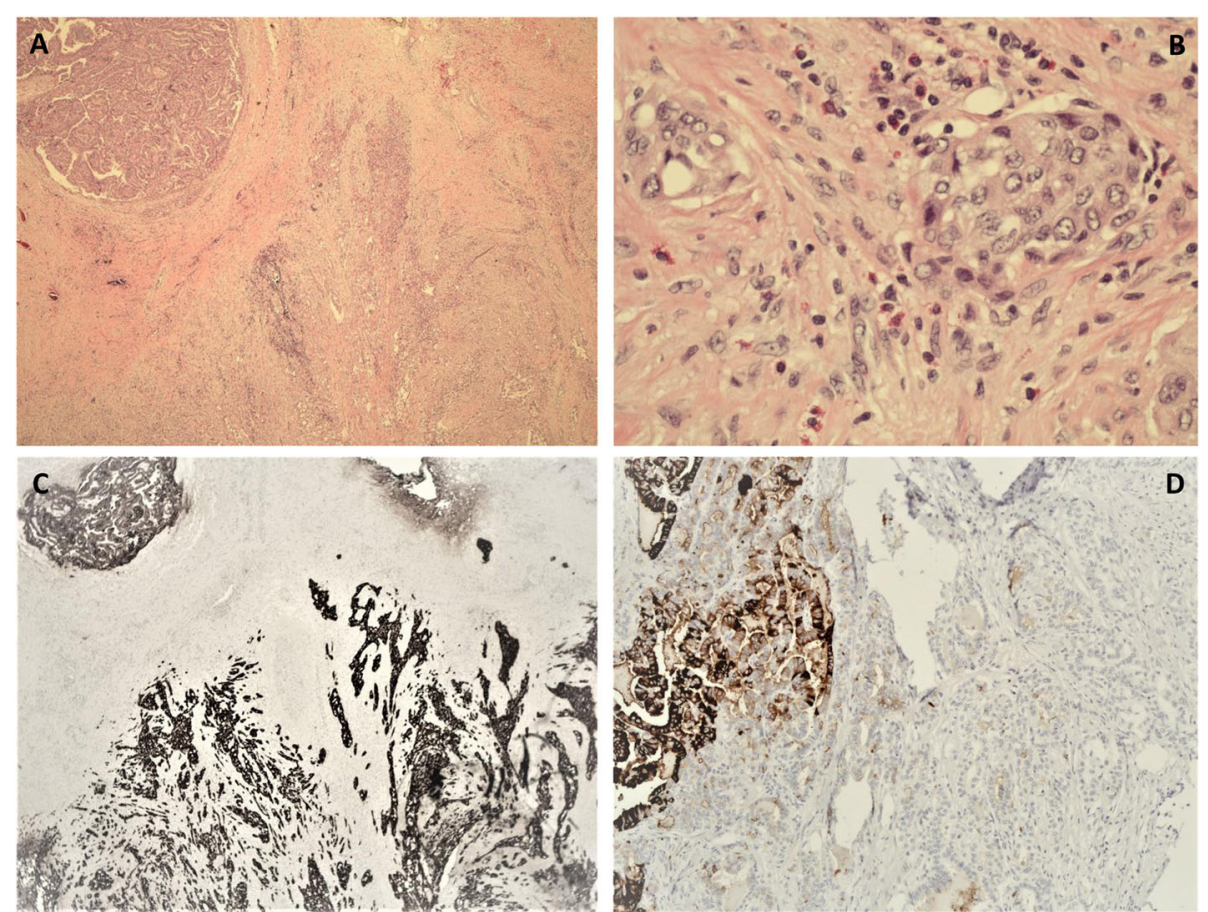

Fig. 3 a Classic papillary thyroid carcinoma (PTC) on left upper corner and sclerosing mucoepidermoid carcinoma with eosinophilia (SMECE) on right lower corner (hematoxylin and eosin (H\&E) stain; original magnification, $\times 2$ ). $\mathbf{b}$ Nests of squamoid cells in a background of fibrous stroma and numerous eosinophils (hematoxylin and eosin (H\&E) stain; original magnification, $\times 40$ ). c Cytokeratin AE1/AE3 stain highlights classic PTC on left upper corner and infiltrating SMECE on right lower corner (IHC; original magnification, $\times 2$ ). $\mathbf{d}$ Thyroglobulin stain is positive in classic PTC and negative in SMECE (IHC; original magnification, $\times 10)$

Surgical pathology showed anaplastic and poorly differentiated thyroid carcinoma, which again tested positive for BRAF V600E mutation. At the time of her last visit, the patient was being considered for radiation therapy and BRAF inhibitor treatment, but insurance did not cover the latter. She was subsequently lost to follow-up.

\section{Discussion and conclusions}

To the best of our knowledge, these are the first published reports of SMECE associated with the activating mutation in the BRAF gene. BRAF V600E mutation is a novel independent molecular prognostic marker in the risk evaluation of thyroid cancer $[8,9]$. It is associated with a poor clinical outcome with more aggressive, invasive tumors that are less ${ }^{131}$ I avid. This is consistent with the clinical presentation of both our patients. Patient 1 had highly aggressive metastatic disease and is the first reported case of SMECE with renal metastasis, to our knowledge. Patient 2 had locally invasive disease with multiple recurrences requiring repeated surgical interventions. Our findings are contrary to a recent paper that reported five patients with SMECE who did not have BRAF mutation by next-generation sequencing [2]. However, none of these cases had distant metastasis. Thus, although $B R A F$ activating mutation may not be present in all SMECE thyroid cancers, it may be a marker for a subset of SMECE tumors that demonstrate more aggressive behavior, as seen in PTC.

Our literature review provides more insight into the characteristics of this rare thyroid cancer. We found 59 cases of SMECE reported in the literature, which are summarized in Tables 1 and 2 along with our 2 cases. Overall, there is a female predominance, with female-to-male ratio of 9:1. Patients ages ranged from 26 to 89 years with a median of 57 years. The mean tumor size, using the largest measured diameter reported, was $4.5 \mathrm{~cm}$ (range $0.5-13 \mathrm{~cm}$ ). On initial presentation, the majority of tumors either occurred in the lateral lobes or diffusely involved the thyroid (98\%), with fewer tumors occurring in the isthmus alone (2\%). Almost all cases had a background of chronic lymphocytic thyroiditis (95\%). We further observed that only seven cases (16\%) had concurrent PTC, two of which were our cases. Thus, although coexisting SMECE and PTC is rare, it can occur. The majority of SMECE cases (95\%) were negative for thyroglobulin, and all were positive for CK, p63, and mucin, whereas none stained for chromogranin or calcitonin. TTF1 and CEA expression was more variable, with $47 \%$ and $75 \%$ of cases demonstrating expression, respectively.

Extrathyroidal extension and lymph node involvement of SMECE were present in $54 \%$ and $40 \%$, respectively, at the time of presentation. Distant metastases were rare (15\%), and sites included bone, liver, lung, peritoneum, and distant 


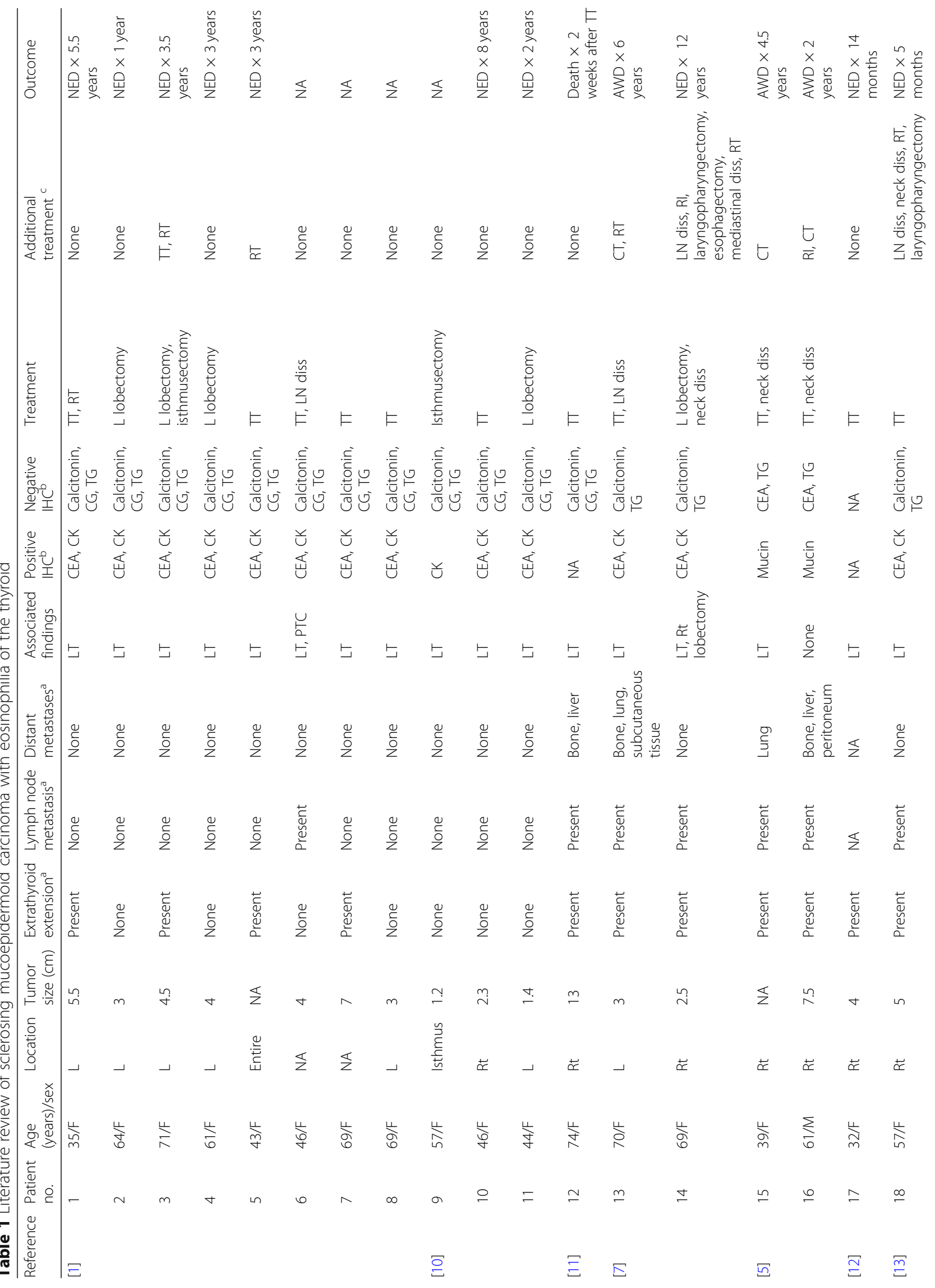




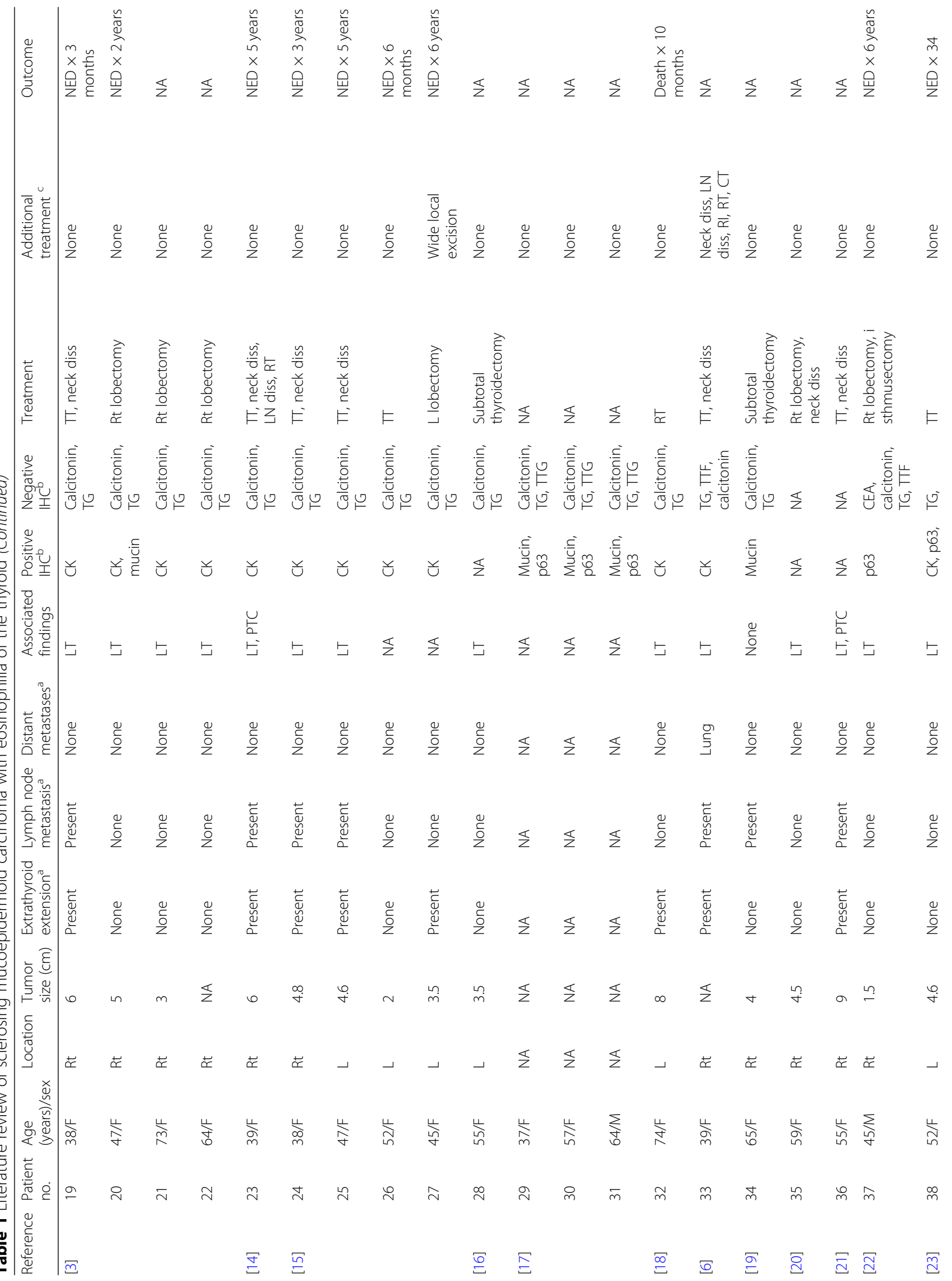




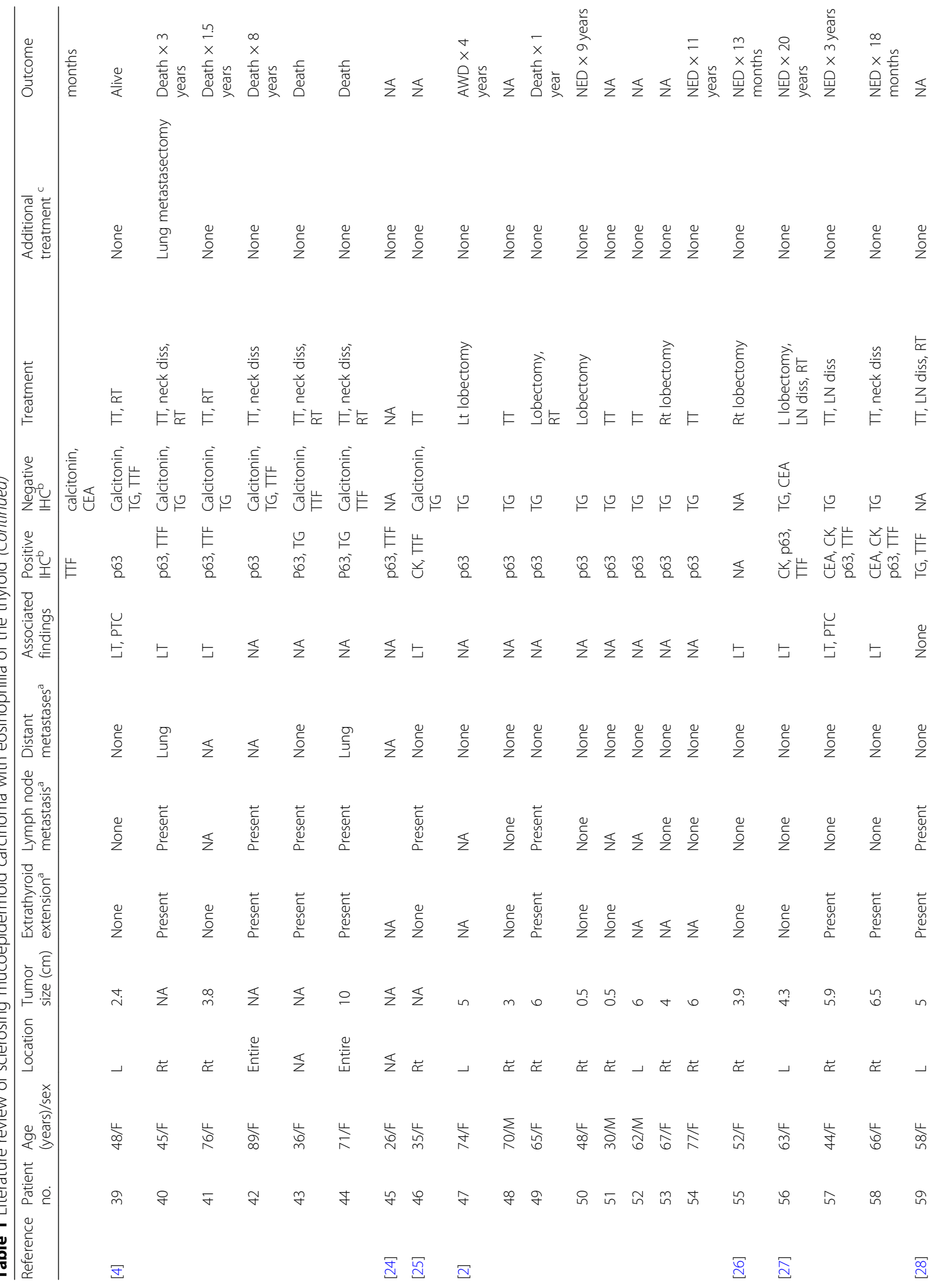




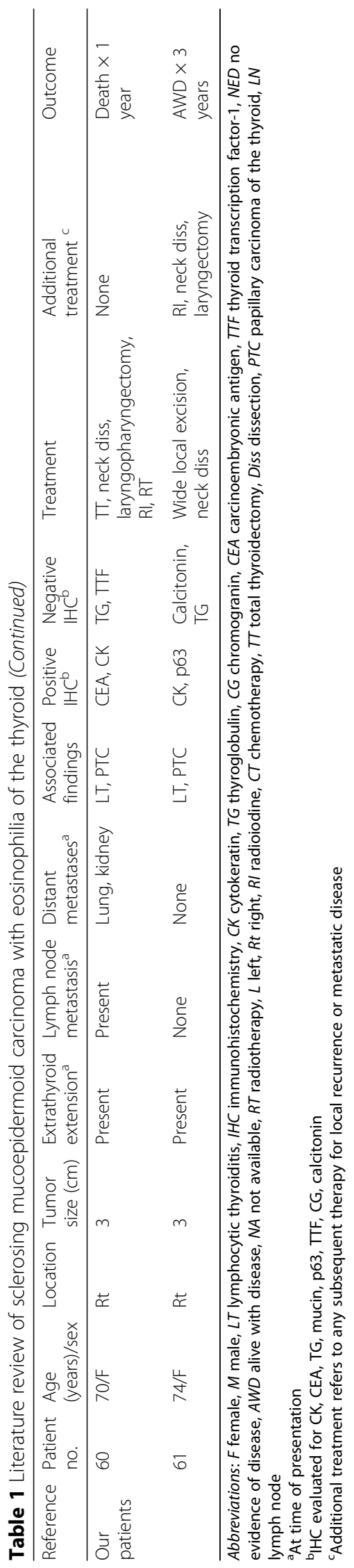


Table 2 Clinical and pathologic features of sclerosing mucoepidermoid carcinoma with eosinophilia of the thyroid

\begin{tabular}{|c|c|}
\hline Feature & Data \\
\hline Age & 26-89 years (median 57) \\
\hline Gender & $55 \mathrm{~F} / 6 \mathrm{M}$ \\
\hline Tumor size $^{a}$ & $0.5-13 \mathrm{~cm}(4.5 \mathrm{~cm}) ; n=49$ \\
\hline Synchronous PTC & $7 / 44(16 \%)$ \\
\hline Background of LT & $42 / 44(95 \%)$ \\
\hline Extrathyroidal extension & 28/52 (54\%) \\
\hline Lymph node metastases & $20 / 50(40 \%)$ \\
\hline Distant metastases & $8 / 54(15 \%)$ \\
\hline \multicolumn{2}{|l|}{ IHC: } \\
\hline Cytokeratin & $32 / 32(100 \%)$ \\
\hline Carcinoembryonic antigen & $16 / 21(76 \%)$ \\
\hline Thyroglobulin & $3 / 56(5 \%)$ \\
\hline Mucin & $7 / 7(100 \%)$ \\
\hline p63 & $24 / 24(100 \%)$ \\
\hline Thyroid transcription factor- 1 & 9/19 (47\%) \\
\hline Chromogranin & 0/12 (0\%) \\
\hline Calcitonin & $0 / 41(0 \%)$ \\
\hline \multicolumn{2}{|l|}{ Outcome data } \\
\hline Alive without disease & $25 / 40(63 \%)$ \\
\hline Alive with disease & $6 / 40(15 \%)$ \\
\hline Deceased & 9/40 (23\%) \\
\hline
\end{tabular}

Abbreviations: $F$ female, $M$ male, $L T$ lymphocytic thyroiditis, $I H C$ immunohistochemistry, PTC papillary carcinoma of the thyroid a Largest dimension of tumor used

subcutaneous tissue, with the lung being most common. Patient 1 had renal metastasis showing SMECE pathology, which has never been reported. Aggregate outcome data of the case reports in our literature review revealed that $63 \%$ of patients were alive and free of disease, $15 \%$ of patients were alive with disease, and $23 \%$ of patients were deceased following initial diagnosis.

Both our patients had BRAF V600E mutation in the SMECE tumor tissue, suggesting involvement of the RASRAF-MEK-ERK signaling pathway in its pathogenesis. This observation opens potential treatment options for this poorly responsive thyroid cancer. We considered targeted therapy in the case of patient 1 but deferred it, given functional decline of the patient. In the case of patient 2, BRAF inhibitors were not covered by insurance. BRAF inhibitors such as vemurafenib and dabrafenib could be useful as targeted medical therapy in the treatment of SMECE. These medications have been approved by the U.S. Food and Drug Administration for the treatment of metastatic melanoma $[29,30]$. They have also shown antitumor efficacy in progressive, BRAF V600E mutant papillary, and anaplastic thyroid cancer when combined with a MEK inhibitor [31, 32]. One limitation of our analysis is the mechanism by which
BRAF V600E mutation was detected. PCR was used because newer techniques of molecular sequencing, such as nextgeneration sequencing, were not widely available at the time of these patients' presentations.

In conclusion, we report the first two cases of SMECE associated with activating BRAF mutation. These findings demonstrate that these tumors should be tested early for $B R A F$ mutation and provide insight into potential mechanisms of the pathogenesis of aggressive subtypes of SMECE. BRAF inhibitors are currently being investigated for use in thyroid cancers as targeted pharmacotherapy and may also prove to be useful in the treatment of a subset of SMECE thyroid cancer.

\section{Acknowledgments \\ We thank Dr. Abhimanyu Garg and Dr. Ildiko Lingvay for their mentorship.}

\section{Authors' contributions}

DP performed the initial literature search and skeletal case report based on patient 1's case. JB performed the BRAF mutation testing and pathology slides for patient 1. SY performed the BRAF mutation testing, skeletal writeup for patient 2, and pathology slides for patient 2 and provided pathology guidance for the report. JSS and SS performed a complete and updated literature search and a review of the literature and were major contributors to the writing of the manuscript. BJW provided clinical information for patient 1 and helped to revise the manuscript. SSH initiated the BRAF mutation testing in the care of patient 1, provided the concept for the case report, and was a major contributor to the writing of the manuscript. All authors read and approved the final manuscript.

Funding

Not applicable.

\section{Availability of data and materials \\ Not applicable.}

Ethics approval and consent to participate

Institutional review board exemption obtained as case series only has two subjects.

\section{Consent for publication}

Institutional review board exemption obtained as case series only has two subjects. The copy of the exemption letter is available for review by the Editor-in-Chief of this journal.

\section{Competing interests}

Dr. Welch reports receiving honoraria from AbbVie for lectures. All other authors have no disclosures or competing financial interests to declare.

\section{Author details}

${ }^{1}$ Department of Internal Medicine, UT Southwestern Medical Center, 5323 Harry Hines Boulevard, Dallas, TX 75390, USA. ²Department of Endocrinology, Capital Diabetes and Endocrine Associates, 5801 Allentown Road, Suite 500,

Camp Springs, MD 20746, USA. ${ }^{3}$ Department of Endocrinology, Baylor University Medical Center, 3500 Gaston Avenue, Dallas, TX 75246, USA. ${ }^{4}$ Department of Pathology, UT Southwestern Medical Center, 5323 Harry Hines Boulevard, Dallas, TX 75390, USA. ${ }^{5}$ Division of Endocrinology, VA North Texas Healthcare System, 4500 South Lancaster Road, Dallas, TX 75216, USA.

Received: 4 July 2019 Accepted: 2 October 2019

Published online: 28 December 2019

\section{References}

1. Chan JK, Albores-Saavedra J, Battifora H, Carcangiu ML, Rosai J. Sclerosing mucoepidermoid thyroid carcinoma with eosinophilia: a distinctive lowgrade malignancy arising from the metaplastic follicles of Hashimoto's thyroiditis. Am J Surg Pathol. 1991;15(5):438-48. 
2. Shah AA, La Fortune K, Miller C, Mills SE, Baloch Z, LiVolsi V, et al. Thyroid sclerosing mucoepidermoid carcinoma with eosinophilia: a clinicopathologic and molecular analysis of a distinct entity. Mod Pathol. 2017;30(3):329-39.

3. Baloch ZW, Solomon AC, LiVolsi VA. Primary mucoepidermoid carcinoma and sclerosing mucoepidermoid carcinoma with eosinophilia of the thyroid gland: a report of nine cases. Mod Pathol. 2000;13(7):802-7.

4. Quiroga-Garza G, Lee JH, El-Naggar A, Black JO, Amrikachi M, Zhai QJ, et al. Sclerosing mucoepidermoid carcinoma with eosinophilia of the thyroid: more aggressive than previously reported. Hum Pathol. 2015;46(5):725-31.

5. Geisinger KR, Steffee $\mathrm{CH}$, McGee RS, Woodruff RD, Buss DH. The cytomorphologic features of sclerosing mucoepidermoid carcinoma of the thyroid gland with eosinophilia. Am J Clin Pathol. 1998;109(3):294-301.

6. Shehadeh NJ, Vernick J, Lonardo F, Madan SK, Jacobs JR, Yoo GH, et al. Sclerosing mucoepidermoid carcinoma with eosinophilia of the thyroid: a case report and review of the literature. Am J Otolaryngol. 2004;25(1):48-53.

7. Sim SJ, Ro JY, Ordonez NG, Cleary KR, Ayala AG. Sclerosing mucoepidermoid carcinoma with eosinophilia of the thyroid: report of two patients, one with distant metastasis, and review of the literature. Hum Pathol. 1997;28(9):1091-6.

8. Xing M. BRAF mutation in thyroid cancer. Endocr Relat Cancer. 2005;12(2):245-62

9. Ball DW. Selectively targeting mutant BRAF in thyroid cancer. J Clin Endocrinol Metab. 2010;95(1):60-1.

10. Wenig BM, Adair CF, Heffess CS. Primary mucoepidermoid carcinoma of the thyroid gland: a report of six cases and a review of the literature of a follicular epithelial-derived tumor. Hum Pathol. 1995;26(10):1099-1108.

11. Bondeson $L$, Bondeson $A G$. Cytologic features in fine-needle aspirates from a sclerosing mucoepidermoid thyroid carcinoma with eosinophilia. Diagn Cytopathol. 1996;15(4):301-305.

12. Cavazza A, Toschi E, Valcavi R, et al. [Sclerosing mucoepidermoid carcinoma with eosinophilia of the thyroid: description of a case]. Pathologica. 1999;91(1):31-35.

13. Chung J, Lee SK, Gong G, et al. Sclerosing Mucoepidermoid carcinoma with eosinophilia of the thyroid glands: a case report with clinical manifestation of recurrent neck mass. J Korean Med Sci. 1999;14(3):338-341.

14. Solomon AC, Baloch ZW, Salhany KE, Mandel S, Weber RS, LiVolsi VA. Thyroid sclerosing mucoepidermoid carcinoma with eosinophilia: mimic of Hodgkin disease in nodal metastases. Arch Pathol Lab Med. 2000;124(3):446-449.

15. Albores-Saavedra J, Gu X, Luna MA. Clear cells and thyroid transcription factor I reactivity in sclerosing mucoepidermoid carcinoma of the thyroid gland. Ann Diagn Pathol. 2003;7(6):348-353.

16. Sharma K, Nigam S, Khurana N, Chaturvedi KU. Sclerosing mucoepidermoid carcinoma with eosinophilia of the thyroid--a case report. Indian J Pathol Microbiol. 2003;46(4):660-661.

17. Hunt JL, LiVolsi VA, Barnes EL. p63 expression in sclerosing mucoepidermoid carcinomas with eosinophilia arising in the thyroid. Mod Pathol. 2004; 17(5):526-529.

18. Kanat Ö, Evrensel T, Tolunay S, et al. Sclerosing mucoepidermoid carcinoma with eosinophilia of the thyroid gland: Description of a case and review of the literature. Turkish Journal of Cancer 2004;34:122-126.

19. Das S, Kalyani R. Sclerosing mucoepidermoid carcinoma with eosinophilia of the thyroid. Indian J Pathol Microbiol. 2008;51(1):34-36.

20. Frazier WD, Patel NP, Sullivan CA. Pathology quiz case 1. Sclerosing mucoepidermoid carcinoma with eosinophilia (SMECE). Arch Otolaryngol Head Neck Surg. 2008;134(3):333, 335.

21. Calò PG, Maxia S, Lai ML, Nicolosi A, Ribuffo D. Sclerosing mucoepidermoid thyroid carcinoma requiring cervical reconstruction: a case report and review of the literature. Am Surg. 2010;76(8):918-919.

22. Lai CY, Chao TC, Lin JD, Hsueh C. Sclerosing mucoepidermoid carcinoma with eosinophilia of thyroid gland in a male patient: a case report and literature review. Int J Clin Exp Pathol. 2015;8(5):5947-5951.

23. Orbeal R, Jimeno J, Monroy G, Badia F, Parés D. [Sclerosing mucoepidermoid carcinoma of the thyroid gland with eosinophilia]. Cir Esp. 2015;93(10):e137-138.

24. Selivanova LS, Tertychnyı̆ AS. [Sclerosing mucoepidermoid carcinoma with eosinophilia of the thyroid gland]. Arkh Patol. 2013;75(5):44-49.

25. Pantola C, Kala S, Athar M, Thakur S. Sclerosing mucoepidermoid carcinoma with eosinophilia of the thyroid: A cytological dilemma. J Cytol. 2016;33(1):37-39.

26. Ames E, Campbell MJ, Afify A, Krane JF, Huang EC. Sclerosing mucoepidermoid carcinoma with eosinophilia: Cytologic characterization of a rare distinct entity in the thyroid. Diagn Cytopathol. 2018;46(7):632-635.

27. Hirokawa M, Takada N, Abe H, et al. Thyroid sclerosing mucoepidermoid carcinoma with eosinophilia distinct from the salivary type. Endocr J. 2018;65(4):427-436.
28. Raveendran Nair AKA, George NA, Kumar R, Sreekumar A, Jayasree K. Sclerosing mucoepidermoid carcinoma with eosinophilia of thyroid gland: Not so indolent a neoplasm? Indian J Pathol Microbiol. 2018;61(2):242-244.

29. Chapman PB, Hauschild A, Robert C, Haanen JB, Ascierto P, Larkin J, et al. Improved survival with vemurafenib in melanoma with BRAF V600E mutation. N Engl J Med. 2011;364(26):2507-16.

30. Hauschild A, Grob JJ, Demidov LV, Jouary T, Gutzmer R, Millward M, et al. Dabrafenib in BRAF-mutated metastatic melanoma: a multicentre, openlabel, phase 3 randomised controlled trial. Lancet. 2012;380(9839):358-65.

31. Song $H$, Zhang J, Ning $L$, Zhang $H$, Chen $D$, Jiao $X$, et al. The MEK $1 / 2$ inhibitor AZD6244 sensitizes BRAF-mutant thyroid cancer to vemurafenib. Med Sci Monit. 2018;24:3002-10.

32. Subbiah V, Kreitman RJ, Wainberg ZA, Cho JY, Schellens JHM, Soria JC, et al. Dabrafenib and trametinib treatment in patients with locally advanced or metastatic BRAF V600-mutant anaplastic thyroid cancer. J Clin Oncol. 2018;36(1):7-13.

\section{Publisher's Note}

Springer Nature remains neutral with regard to jurisdictional claims in published maps and institutional affiliations.
Ready to submit your research? Choose BMC and benefit from:

- fast, convenient online submission

- thorough peer review by experienced researchers in your field

- rapid publication on acceptance

- support for research data, including large and complex data types

- gold Open Access which fosters wider collaboration and increased citations

- maximum visibility for your research: over $100 \mathrm{M}$ website views per year

At $\mathrm{BMC}$, research is always in progress.

Learn more biomedcentral.com/submissions 